\title{
A modified maximum tangential stress criterion for determination of the fracture toughness in bi-material notches - Part 1: Theory
}

\author{
M. M. Mirsayar*
}

Zachry Department of Civil Engineering, Texas A\&M University, College Station, TX 77843-3136, USA

\begin{tabular}{|c|c|}
\hline $\begin{array}{l}\text { ARTICLE INFO } \\
\end{array}$ & A B S T RACT \\
\hline $\begin{array}{l}\text { Article history: } \\
\text { Received June } 6,2014 \\
\text { Accepted } 2 \text { August } 2014 \\
\text { Available online } \\
4 \text { August } 2014 \\
\text { Keywords: } \\
\text { Bi-material } \\
\text { Notch } \\
\text { Modified MTS criterion }\end{array}$ & $\begin{array}{l}\text { The effect of first nonsingular stress term of elastic stress field on fracture toughness around bi- } \\
\text { material notch tip is studies in this paper. First, a modified maximum tangential stress criterion } \\
\text { (MMTS) is proposed for determination of the fracture toughness at the tip of the interface } \\
\text { notches. The proposed criterion takes into account the effect of first nonsingular stress term as } \\
\text { well as the singular stress terms. Then, the effect of I-stress on determination of the fracture } \\
\text { toughness is studied analytically. Finally, the proposed criterion is applied on a finite element } \\
\text { (FE) simulated laboratory specimen. A very good correlation was observed between the FE } \\
\text { results and theoretical predictions. }\end{array}$ \\
\hline
\end{tabular}

(C) 2014 Growing Science Ltd. All rights reserved.

\section{Introduction}

Bi-material joints can be seen in many engineering applications ranging from civil and mechanical engineering to the microelectronics industries (Chen et al., 1997; Dunn et al,. 2000; Labossierea et al., 2002; Lu et al., 2002). For instance, ceramic/ metal/ ceramics and ceramic/ ceramic bonded joints are extensively used in airplane and aircraft bodies. At the interface of these bonded joints, stress singularities exist as a result of geometrical configuration and/ or material discontinuity. Therefore the study of stress field around bi-material notch tip is very important.

According to the linear elastic fracture mechanics (LEFM), the elastic stress field near the bi-material notch tip could be expressed as a series expansion containing singular and nonsingular terms. The first, and sometimes the second, terms are singular which means that the eigenvalues of the characteristic equation are less than one. Excluding the singular terms, the rest of the series expansion terms are considered as nonsingular stress terms. The elastic stress field near bi-material notch tip is studied in the past by many researchers (Ayatollahi et al., 2010 a,b, 2011; Mirsayar et al., 2014a;

* Corresponding author. Tel.: +1 (979) 777-6096

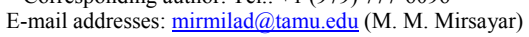


Arabi et al., 2013; Mirsayar and Samaei 2013, 2014; Mirsayar, 2013). The effect of first nonsingular stress field around the bi-material notch tip on the photoelastic fringe patterns is studied by Ayatollahi et al. (2011). Also, the effect of first nonsingular stress term of elastic stress field around bi-material and simple cracks and simple notches has also been investigated by many researchers (Mirsayar, 2014a,b; Ayatollahi et al., 2006, 2013; Ayatollahi and Aliha, 2007 Ayatollahi and Mirsayar, 2011).

Fig. 1 illustrates a typical bi-material notch at the interface of two homogeneous linear elastic solids. The area $0 \leq \theta \leq \theta_{1}$ belongs to material 1 and the area $0 \leq \theta \leq \theta_{2}$ represents the material 2 . The elastic stress field near the bi-material notch tip can be expressed as:

$$
\begin{aligned}
& \sigma_{m, i j}=\sum_{k=1}^{N} H_{k} r^{\lambda_{k}-1} f_{m, i j, k} \\
& u_{m, i}=\sum_{k=1}^{N} H_{k} r^{\lambda_{k}} g_{m, i, k}
\end{aligned}
$$

where $(i, j) \equiv(r, \theta)$ are the polar coordinates with the origin at the bi-material notch tip, $m=1,2$ denotes the material number and $\lambda_{\mathrm{k}}$ corresponds to the $k$ th eigenvalue of the problem. Also in Eq. (1), $f_{i j k}$ and $g_{i k}$ are functions of elastic properties of the materials, eigenvalues $\lambda_{k}$, the local edge geometry characterized by the angles $\theta_{1}$ and $\theta_{2}$ and the polar coordinate $\theta$. The eigenvalues of a bi-material problem are obtained by solving numerically a characteristic equation and, contrary to the homogeneous notch eigenvalues, they depend not only on the edge geometrical configuration characterized by $\theta_{1}$ and $\theta_{2}$ but also on the elastic properties of the two materials. Although $\lambda_{\mathrm{k}}$ could be either a real or a complex number depending on the general configuration of the bi-material notch, Eq. (1) is valid only for positive real values of $\lambda_{k}$. In addition, $H_{k}$ is the unknown coefficient of the stress field corresponding to the eigenvalue $\lambda_{\mathrm{k}}$ and is called the bi-material notch stress intensity associated with the eigenvalue $\lambda_{\mathrm{k}}$. The calculation process for determination of the eigenvalues and stress intensities are given in details in Ayatollahi et al., (2010a).

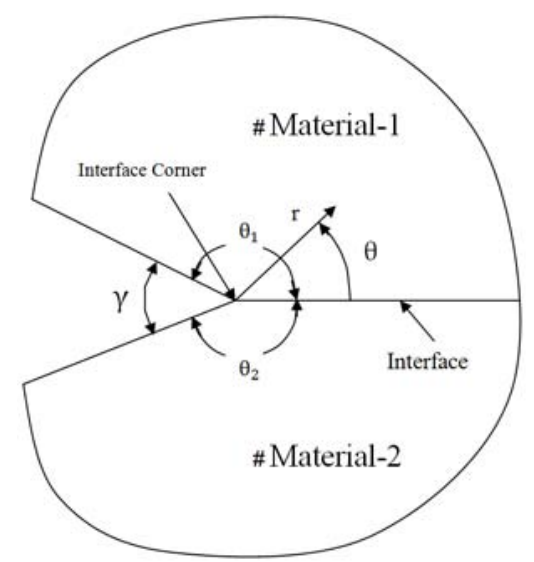

Fig. 1. General configuration of the bi-material notch made of materials 1 and 2.

Many of fracture criteria have been proposed so far for determining the fracture toughness near the bi-material notch tip. Labossierea et al. (2002) and Dunn et al. (2000) proposed a stress intensity based fracture criterion for estimation of the fracture initiation at the tip of interface notches. Mirsayar (2014b), proposed a fracture criterion for bi-material cracks taking into account the effect of T-stress. Some researchers proposed a fracture criterion for determination of the kinking angle and fracture toughness at the bi-material notch tip based on strain energy density concept considering only the effect of singular stress terms (Klusak and Knsel, 2007; Spyropoulos, 2003). Many of the recently published papers demonstrated that the first nonsingular stress term of the elastic stress field may significantly affect the stress distribution around the bi-material notch tip. Mirsayar et al. (2014b), proposed a fracture criterion for determination of the kinking angle at the interface notch tip 
introducing the modified maximum tangential stress (MMTS) criterion. In this paper, the MMTS is applied on a FE specimen and the fracture toughness is predicted using the MMTS criterion and compared with the FE results. It is shown that the MMTS prediction is in a very good consistency with the FE results.

\section{Tangential stress based criteria}

\subsection{MTS criterion}

One of the most well-known fracture criteria which has been widely used so far for simple cracks and notches is the maximum tangential stress (MTS) criterion. Although the MTS is not widely used for bi-material systems, it utilizes a simple idea for the fracture phenomenon especially in brittle materials and is extended well for simple cracks (Awaji and Sato 1978; Shetty et al. 1987; Singh and Shetty 1989; Tikare and Choi 1997; Aliha and Ayatollahi 2008, 2009, 2012; Ameri et al. 2012; Ayatollahi and Aliha 2011, Aliha et al. 2008, 2012; Yamauchi et al. 2011). According to this criterion, fracture occurs at the notch tip when the maximum tangential stress reaches its critical value $\left(\sigma_{c}\right)$ at a critical distance, $d$, around the notch tip in one of the materials. Using this definition, the fracture toughness at the interface could be represented as:

$$
H_{1 C, m}=\frac{2 K\left(M_{m}\right)_{I C} /(\sqrt{2 \pi})}{\frac{d^{\lambda_{1}-\frac{1}{2}}}{\lambda_{1}} F_{m, \theta \theta, 1}\left(\theta_{0}\right)+\Gamma_{21} \frac{d^{\lambda_{2}-\frac{1}{2}}}{\lambda_{2}} F_{m, \theta \theta, 2}\left(\theta_{0}\right)}
$$

In Eq. (2), $K\left(M_{m}\right)_{I C}$ is the fracture toughness of the material in which the crack propagates. Also, $\Gamma_{21}=\frac{H_{2}}{H_{1}}$ and $\theta_{0}$ represents the fracture initiation angle at the interface corner. The $\theta_{0}$ is the direction where the tangential stress reaches to its critical value at the critical distance, $d$, around the bimaterial notch tip and could be calculated as:

$\frac{\partial \bar{\sigma}_{m, \theta \theta}}{\partial \theta}=0 \rightarrow \frac{d^{\lambda_{1}-1}}{\lambda_{1}} \frac{\partial F_{m, \theta \theta, 1}}{\partial \theta}+\frac{H_{2}}{H_{1}} \frac{d^{\lambda_{2}-1}}{\lambda_{2}} \frac{\partial F_{m, \theta \theta, 2}}{\partial \theta}=0 \quad\left(\frac{\partial^{2} \bar{\sigma}_{m, \theta \theta}(\theta)}{\partial \theta^{2}}\right)_{\theta_{0}}<0$

In Eq. (3), only the singular stress terms are considered and the effect of nonsingular stress terms is not considered. As mentioned before, the first nonsingular stress term (I-stress) sometimes plays an important role in stress distribution around the interface notch tip. Therefore the effect of I-stress on fracture toughness needs to be studied.

\subsection{Modified MTS (MMTS) criterion}

The Eq. (2) and (3) can be rewritten by taking into account the I-stress term as well as the singular stress terms as:

$$
\begin{aligned}
& \frac{\partial \bar{\sigma}_{m, \theta \theta}}{\partial \theta}=0 \rightarrow \frac{d^{\lambda_{1}-1}}{\lambda_{1}} \frac{\partial F_{m, \theta \theta, 1}}{\partial \theta}+\left[\cot \left(\frac{\pi M^{e}}{2}\right)\right] \frac{d^{\lambda_{2}-1}}{\lambda_{2}} \frac{\partial F_{m, \theta \theta, 2}}{\partial \theta}+\Gamma_{31} \frac{d^{\lambda_{3}-1}}{\lambda_{3}} \frac{\partial F_{m, \theta \theta, 3}}{\partial \theta}=0 \rightarrow \theta_{0} \\
& H_{1 C}=\frac{2 K_{I C} / \sqrt{2 \pi}}{\frac{d^{\lambda_{1}-\frac{1}{2}}}{\lambda_{1}} F_{m, \theta \theta, 1}\left(\theta_{0}\right)+\left[\tan \left(\frac{\pi M^{\prime e}}{2}\right)\right] \frac{d^{\lambda_{2}-\frac{1}{2}}}{\lambda_{2}} F_{m, \theta \theta, 2}\left(\theta_{0}\right)+\Gamma_{31} \frac{d^{\lambda_{3}-\frac{1}{2}}}{\lambda_{3}} F_{m, \theta \theta, 3}\left(\theta_{0}\right)}
\end{aligned}
$$

where, $\Gamma_{31}=\frac{H_{3}}{H_{1}}, M^{e}=\frac{2}{\pi} \tan ^{-1}\left(\frac{H_{1}}{H_{2}}\right)$ and $M^{\prime e}=\frac{2}{\pi} \tan ^{-1}\left(\Gamma_{21}\right)$. To study the effect of combination of the materials, the elastic mismatch parameters are selected as $\alpha=0.2$ and $\beta=\alpha / 4$. In fact, $\beta=\alpha / 4$ path in 
$\alpha-\beta$ space cover the most important bonded joints in engineering application (Ayatollahi et al., 2010a). The elastic mismatch parameters $\alpha$ and $\beta$ could be expressed as:

$$
\begin{aligned}
& \alpha=\frac{\mu_{1}\left(\kappa_{2}+1\right)-\mu_{2}\left(\kappa_{1}+1\right)}{\mu_{1}\left(\kappa_{2}+1\right)+\mu_{2}\left(\kappa_{1}+1\right)} \\
& \beta=\frac{\mu_{1}\left(\kappa_{2}-1\right)-\mu_{2}\left(\kappa_{1}-1\right)}{\mu_{1}\left(\kappa_{2}+1\right)+\mu_{2}\left(\kappa_{1}+1\right)}
\end{aligned}
$$

In this equation, $E_{m}, v_{m}$ and $\mu_{m}=E_{m} / 2\left(1+v_{m}\right)$ are the Young's modulus, Poisson's ratio and shear modulus associated with the material $\mathrm{m}(\mathrm{m}=1,2)$, respectively. The Kolosov constant $\kappa_{\mathrm{m}}$ is equal to 3$4 v_{\mathrm{m}}$ for the plane strain and $\left(3-v_{\mathrm{m}}\right) /\left(1+v_{\mathrm{m}}\right)$ for the plane stress conditions. It is clear that as $\mu_{1} / \mu_{2} \rightarrow \infty$ or $\mu_{1} / \mu_{2} \rightarrow 0$, the mismatch parameter $\alpha$ approaches +1 or -1 , respectively. Also by applying the restriction of $0<v_{\mathrm{m}}<1 / 2$ to the parameter $\kappa_{\mathrm{m}}$ and considering the plane strain conditions, the parameter $\beta$ varies only between $\beta=(\alpha+1) / 4$ and $\beta=(\alpha-1) / 4$ in terms of parameter $\alpha$. Consequently, for the plane strain condition under the restrictions of $0<v_{\mathrm{m}}<1 / 2$ and $0<\mu_{\mathrm{m}}<\infty$, all the values of mismatch parameters $\alpha$ and $\beta$ are contained within a parallelogram enclosed $\alpha= \pm 1$ and $\alpha-4 \beta= \pm 1$ in the $\alpha-\beta$ plane. The range of $\alpha$ and $\beta$ in plane stress is somewhat more restricted. The point $\alpha=\beta=0$ corresponds to a homogeneous notch with identical materials. The sign of $\alpha$ depends on the relative stiffness of materials 1 and 2 . The variation of the fracture toughness versus $M^{\prime e}$ is illustrated in Fig. 2 for opening angle of $\gamma=30^{\circ}$. It could be seen that the I-stress has a significant effect on the fracture toughness at the interface corner. These effects are important at $M^{\prime e}=0$ and increase at the first and then decrease by increasing the $M^{\prime} e$. It also can be seen that for negative values of $\Gamma_{31}$, the estimated fracture toughness using MTS is less than that of estimated by MMTS and vice versa.

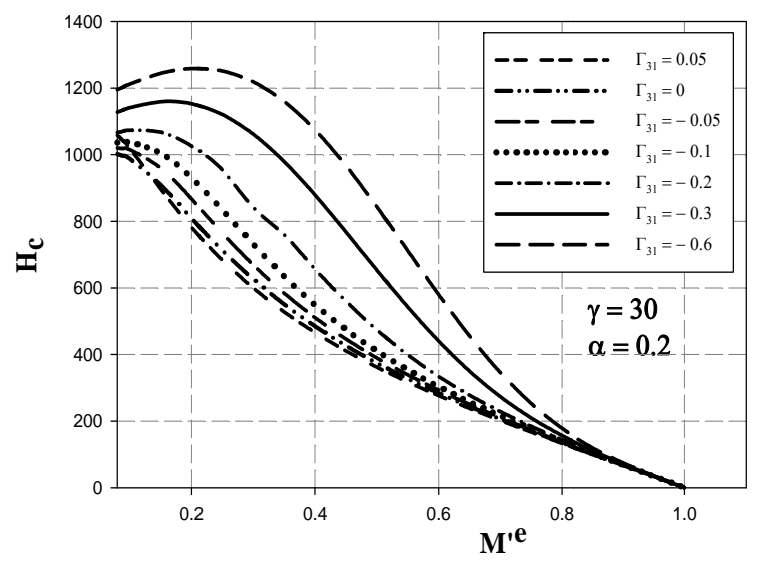

Fig. 2. Variation of the fracture toughness versus for $\left(\alpha=0.2, \gamma=30^{\circ}\right)$

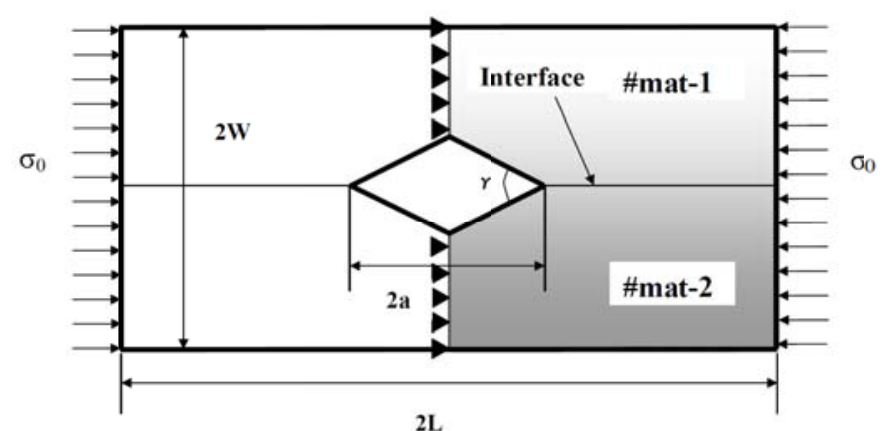

Fig. 3. Centrally notched rectangular plate under uniaxial compression (CNRC)

\section{Finite Element Example}

To evaluate the MMTS criterion in estimation of the fracture toughness, a laboratory specimen is modeled using finite element software ABAQUS. The specimen is called centrally notched rectangular plate under uniaxial compression (CNRC) and is shown in Fig. 3. The fracture toughness values are determined for the specimen using both MTS and MMTS criteria and are compared with that of calculated from finite element analysis. To calculate the stress intensity factors and I-stress, a numerical method, called FEOD, is employed. In this approach, the series solution of displacement fields around the crack tip is fitted to a large number of nodal displacements obtained from the nodes surrounding the crack tip. Consequently, an over-determined set of simultaneous linear equations is obtained and the nodal displacements reduce to a small set of unknown coefficients by employing the 
least-squares method. More details about this numerical method could be found in Ayatollahi et al., (2010a).

The finite element results as well as the MTS and MMTS predictions are given in Table 1 at the critical distance of $d=0.5 \mathrm{~mm}$. It can be seen that MMTS criterion provides more accurate prediction of the fracture toughness and kinking angle than the conventional MTS criterion.

Table 1. Estimation of the fracture initiation condition using MTS and MMTS

\begin{tabular}{ccccc}
\hline$(\mathrm{d}=0.5 \mathrm{~mm})$ & $\Gamma_{21}$ & $\Gamma_{31}$ & $\theta_{0}(\mathrm{Deg})$ & $\mathrm{H}_{1 \mathrm{c}} / \mathrm{K}_{\mathrm{Ic}}$ \\
\hline MTS & 0.17 & -0.33 & -8 & 0.82 \\
MMTS & - & - & -13.5 & 1.15 \\
FEM & - & - & -13.5 & 1.15 \\
\hline
\end{tabular}

\section{Conclusion}

The effect of I-stress on fracture toughness at the bi-material notch tip was studied. The MTS and MMTS criterion were introduced and the effect of sign and value of the I-stress in prediction of the fracture toughness was studied. It was shown that the MTS criterion estimates the fracture toughness less than MMTS when the I-stress is negative and vice versa. A numerical simulation is done on a laboratory specimen and MTS, MMTS and numerical results were compared with each other. It was shown that MMTS provides more accurate results than the MTS in prediction of the fracture toughness and fracture initiation angle.

\section{References}

Aliha, M. R. M., \& Ayatollahi, M. R. (2008). On mixed-mode I/II crack growth in dental resin materials. Scripta Materialia, 59(2), 258-261.

Aliha, M. R. M., \& Ayatollahi, M. R. (2009). Brittle fracture evaluation of a fine grain cement mortar in combined tensile-shear deformation. Fatigue \& Fracture of Engineering Materials \& Structures, 32(12), 987-994.

Aliha, M. R. M., Ayatollahi, M. R., \& Pakzad, R. (2008). Brittle fracture analysis using a ring-shape specimen containing two angled cracks. International Journal of Fracture, 153(1), 63-68.

Aliha, M. R. M., \& Ayatollahi, M. R. (2012). Analysis of fracture initiation angle in some cracked ceramics using the generalized maximum tangential stress criterion. International Journal of Solids and Structures, 49(13), 1877-1883.

Aliha, M. R. M., Ayatollahi, M. R., \& Akbardoost, J. (2012). Typical upper bound-lower bound mixed mode fracture resistance envelopes for rock material. Rock Mechanics and Rock Engineering, 45(1), 65-74.

Ameri, M., Mansourian, A., Pirmohammad, S., Aliha, M. R. M., \& Ayatollahi, M. R. (2012). Mixed mode fracture resistance of asphalt concrete mixtures. Engineering Fracture Mechanics, 93, 153167.

Arabi, H., Mirsayar, M. M., Samaei, A. T., \& Darandeh, M.(2013) Study of Characteristic Equation of the Elastic Stress Field Near Bimaterial Notches. Strength of Materials 45 (5), 598-606.

Awaji, H., \& Sato, S. (1978). Combined mode fracture toughness measurement by the disk test. Journal of Engineering Materials and Technology, 100(2), 175-182.

Ayatollahi, M. R., \& Aliha, M. R. M. (2007). Wide range data for crack tip parameters in two disctype specimens under mixed mode loading. Computational materials science, 38(4), 660-670.

Ayatollahi, M. R., Aliha, M. R. M., \& Hassani, M. M. (2006). Mixed mode brittle fracture in PMMA - an experimental study using SCB specimens. Materials Science and Engineering: A, 417(1), 348-356.

Ayatollahi, M. R., Dehghany, M., \& Mirsayar, M. M. (2013). A comprehensive photoelastic study for mode I sharp V-notches. European Journal of Mechanics-A/Solids 37, 216-230 
Ayatollahi, M. R., Mirsayar, M. M., \& Nejati, M. (2010a). Evaluation of first non-singular terms in biomaterial notches. Computational Material Science, 50 (2), 752-760.

Ayatollahi, M. R., Nejati, M., Mirsayar, M. M.(2010b). An overdeterministic method for stress analysis of bi-material corners and interface cracks using finite element method, Proceedings of the 9th Conference of Iranian Aerospace Society, Tehran, Iran.

Ayatollahi, M. R., Mirsayar, M. M., \& Dehghany, M. (2011). Experimental determination of stress field parameters using photoelasticity. Materials \& Design, 32 (10), 4901-4908.

Ayatollahi, M. R. \& Mirsayar, M. M., (2011). Kinking angle for interface cracks. Procedia Engineering 10, 325-329.

Ayatollahi, M. R., \& Aliha, M. R. M. (2011). Fracture analysis of some ceramics under mixed mode loading. Journal of the American Ceramic Society, 94(2), 561-569.

Chen, W.T., Read, D., Questad, D., \& Sammakia, B., (1997). Opportunities and needs for interfacial fracture mechanics in microelectronic packaging industry. Application of Fracture Mechanics in Electronic Packaging, ASME, AMD-Vol. 222/EEP- 20, 183-192.

Dunn, M. L., Cunningham, S. J. \& Labossierea, P.E.W. (2000) Initiation toughness of Silicon/ Glass anodic bonds. Acta materialia. (48), 735-744.

Klusak J., \& Knesl, Z. (2007). Determination of crack initiation direction from a bi-material notch based on the strain energy density concept. Computational Materials Science 39, 214-218.

Labossierea, P.E.W., Dunn,M. L., \& Cunningham,S. J. (2002). Application of bimaterial interface corner failure mechanics to silicon/ glass anodic bonds. Journal of the Mechanics and Physics of Solids, 50, $405-433$.

Lu, T. J., Moore, D. F., \& Chia, M. H. (2002). Mechanics of micromechanical clips for optical fibers, Journal of Micromechanics and Microengineering. (12) 168-176.

Mirsayar, M. M., \& Samaei, A. T. (2013). Photoelastic study of bi-material notches: Effect of mismatch parameters. Engineering Solid Mechanics 1 (1), 21-26.

Mirsayar, M. (2013). Calculation of stress intensity factors for an interfacial notch of a bi-material joint using photoelasticity. Engineering Solid Mechanics,1(4), 149-153.

Mirsayar, M. M. (2014a). A new mixed mode fracture test specimen covering positive and negative values of T-stress. Engineering Solid Mechanics 2 (2), 67-72.

Mirsayar, M. M. (2014b). On fracture of kinked interface cracks - The role of T-stress. Materials \& Design 61, $117-123$.

Mirsayar, M. M., Aliha, M. R. M., \& Samaei, A. T. (2014). On fracture initiation angle near bimaterial notches-Effects of first non-singular stress term. Engineering Fracture Mechanics, 119, 124-131.

Mirsayar, M. M., \& Samaei, A. T. (2014). Application of maximum tangential stress criterion in determination of fracture initiation angles of silicon/glass anodic bonds. Engineering Solid Mechanics 2 (3), 145-150.

Shetty, D. K., Rosenfield, A. R., \& Duckworth, W. H. (1987). Mixed-mode fracture in biaxial stress state: application of the diametral-compression (Brazilian disk) test. Engineering Fracture Mechanics, 26(6), 825-840.

Singh, D., \& Shetty, D. K. (1989). Microstructural effects on fracture toughness of polycrystalline ceramics in combined mode I and mode II loading. Journal of Engineering for Gas Turbines and Power, 111(1), 174-180.

Spyropoulos, C.P. (2003). Crack initiation direction from interface of bonded dissimilar media. Theoretical and Applied Fracture Mechanics. 39, 99-105.

Tikare, V., \& Choi, S. R. (1997). Combined Mode I-Mode II Fracture of 12-mol\%-Ceria-Doped Tetragonal Zirconia Polycrystalline Ceramic. Journal of the American Ceramic Society, 80(6), 1624-1626.

Yamauchi, Y., Nakano, M., Kishida, K., \& Okabe, T. (2001). Measurement of mixed-mode fracture toughness for brittle materials using edge-notched half-disk specimen. Journal of Society of Materials Science of Japan, 50, 229-234. 